\title{
Aproximación a un estado del arte sobre prácticas de medicina tradicional y popular en Hispanoamérica ${ }^{1}$
}

\author{
Approach to a State of the Art of Traditional and \\ Popular Medicinal Practices in Hispano-American
}

Omar Alberto Garzón Chiriví

\section{Resumen}

Este artículo presenta un estado del arte de la producción académica sobre medicinas tradicionales y populares en Hispanoamérica. Se analiza la relación entre los estudios de chamanismo en comunidades indígenas en algunos países de habla española (Colombia, Perú, Bolivia, México, España) con estudios de curanderismo en contextos urbanos, mostrando la recurrencia de elementos de orden mágico, religioso y médico en sus prácticas terapéuticas. De igual manera, evidencia las mutaciones en las miradas sobre estos sistemas de tratamiento y atención de la salud y la enfermedad, su permanencia e incidencia sobre prácticas colectivas asociadas con la espiritualidad, con la construcción de alternativas de salud individual y social y el carácter interdisciplinario de las investigaciones. Así mismo, indica la existencia de vacíos analíticos en aspectos como género, clase y etnia, en los estudios de medicinas tradicionales y populares.

Palabras clave

Medicina tradicional, medicina popular, estado del arte, curanderismo, curanderos.

Abstract

This article presents a state of the art of academic production concerning traditional and popular medicine in Latin America. It analyzes the relation between studies on chamanismo (the art of medicine men) in indigenous communities in some Spanish-speaking countries (Colombia, Peru, Bolivia, Mexico, Spain) and studies on curanderismo (the art of healers) in urban contexts and evidences recurring elements of a magical, religious and medical kind in their therapeutic practices. Likewise, it shows the changes in the understanding of these systems of treatment and assistance to health and sickness, their permanence and incidence on collective practices associated to spirituality, as well as the construction of alternatives of individual and social health and the interdisciplinary character of the existing research studies. This article, too, proposes the existence of an analytical vacuum regarding gender, class and ethnic group in the studies on traditional and popular medicine.

Keywords

Traditional Medicine, Folk Medicine, State of the Art, Quackery, Witch Doctor.

Artículo recibido el 31 de julio de 2014 - aprobado el 30 de octubre de 2014

1 Este artículo es un avance del trabajo de investigación "Prácticas y usos de medicinas tradicionales mestizas en el cuidado y la atención de la salud y la enfermedad en tres espacios socioculturales en Colombia: Mitú, Bogotá, Medellín", adelantado en el marco del Doctorado en Ciencias Humanas y Sociales de la Universidad Nacional de Colombia.

2 Universidad Distrital Francisco José de Caldas, Bogotá (Colombia). Doctorado en Ciencias Humanas y Sociales, Universidad Nacional de Colombia, Grupo de investigación PROCIRCAS, Universidad Nacional de Colombia, sede Medellín; Grupo de investigación Cyberia, Universidad Distrital Francisco José de Caldas, Bogotá (Colombia). Correo electrónico: oalberto18@ gmail.com 


\section{Introducción}

En su estudio clásico sobre los azande, Evans-Pritchard (1976, p. 440) llamaba curandería al arte de curar, definía al médico tradicional zande como curandero y drogas a los elementos empleados para curar. En su trabajo "Antropología estructural" (1995) Levi Strauss identifica tres elementos indisociables y que constituyen el principio de la curación en el chamanismo estudiado por él: el chamán propiamente dicho, el enfermo y la comunidad (p.162). De estos trabajos fundantes de la antropología se van a desprender múltiples estudios de sistemas mágicos/religiosos que constituyen la base del chamanismo y de una vertiente de este: el curanderismo, con variantes campesinas y urbanas que funciona a partir de los principios anotados.

La producción académica revisada y analizada en este artículo evidencia las mutaciones de esta práctica curativa cultural en distintos contextos, su permanencia y su incidencia en prácticas colectivas asociadas con la espiritualidad y con la construcción de alternativas de salud individual y social. En tanto la práctica muta, los estudios amplían su foco de análisis y las políticas de salubridad a nivel global las incorpora como una alternativa de salud; razón por la cual se hace importante este estado del arte.

\section{El chamanismo como fuente de saber de las medicinas tradicionales y populares: estudios antropológicos}

Desde la antropología se ha producido el mayor número de estudios acerca del tema del chamanismo $^{3}$ en comunidades indígenas en Colombia y América Latina. Estos trabajos han estado a cargo de la etnología y la antropología, principalmente. Los mismos focalizan su análisis en comunidades específicas y en la figura del chamán o curaca. Describen sus técnicas extáticas y analizan la importancia social, cultural y política de su figura dentro

3 En el tema del chamanismo, el trabajo más importante de la literatura clásica, desde una perspectiva comparativa y desde el enfoque de la historia de las religiones es el de Mircea Eliade (1994) El chamanismo y las técnicas arcaicas del éxtasis. de su respectivo grupo. Metodológicamente, son trabajos realizados desde la perspectiva de trabajo de campo en extenso, que implica al antropólogo o etnólogo convivir con el grupo objeto de su investigación. Se destacan fundamentalmente las investigaciones de: Gerardo Reichel-Dolmatoff $(1978$; 1997) con los indios desana en el Vaupés colombiano; Juan Álvaro Echeverri (1993) quien en Tabaco frío, coca dulce recopila la tradición oral del abuelo uitoto (Medio río Caquetá) Hipólito Candre-Kinerai; Patrice Bidou (1988) y Michel Perrin (1988) realizaron investigaciones acerca de la estructura, funcionamiento y formas de comunicación del discurso chamanico en comunidades indígenas de la amazonia colombiana y wayuu de La Guajira colombiana y venezolana; y Luis Cayón (2002) exploró el chamanismo macuna del río Apaporis en Colombia. Una investigación importante y extensa sobre chamanismo en Suramérica, puntualmente en Perú, es Ver, saber, poder. El chamanismo de los yagua en la Amazonia peruana del etnólogo y antropólogo francés Jean Pierre Chaumeil (1998), trabajo de tesis doctoral en antropología social publicado en francés en 1983 y en versión al español en 1998. La importancia de este estudio radica en la mirada que hace sobre las prácticas de los chamanes más allá del ámbito de las comunidades indígenas, con población mestiza.

Estos trabajos analizan aspectos de las cosmogonías indígenas a partir de las cuales fundamentan sus prácticas curativas. Aspectos como la relación hombre/naturaleza y humano/no humano, hacen parte de un conjunto de principios ecológicos de los chamanes, orientados a cumplir una función social colectiva (Reichel-Dolmatof, 1997, p. 9) y que con variantes y ajustes a las necesidades de contexto, han sido incorporadas en algunas prácticas de curandería. En este sentido son un punto de partida para la comprensión de los saberes y las prácticas de la medicina tradicional y popular ${ }^{4}$.

4 El debate acerca del tema de lo populary lo tradicional se puede ampliar en Martín-Barbero y Ochoa (2005), Amselle (2008) y MacClancy (2002). 


\section{Prácticas mágicas y curanderismo en los estudios históricos}

Como objeto de estudio histórico, tres investigaciones evidencian la presencia de prácticas de medicina tradicional en el continente americano. El primero de Diana Luz Ceballos Gómez (2002) quien analiza las prácticas mágico-médicas en el Nuevo Reino de Granada. Esta investigación resulta relevante porque presenta la manera como distintas prácticas mágicas, de hechicería, brujería, adivinación, yerbatería, curanderismo, medicina y chamanismo, propias de América y provenientes de Europa y África, se encontraron y mezclaron para conformar lo que la autora denomina mestizaje cultural (Ceballos, 2002, p. 105). Este trabajo permite una definición de dichas prácticas mágicas como sistemas simbólicos que constituyen "un aparato cognitivo, de carácter simbólico, mediante el cual se interpreta el mundo" (p. 101).

El segundo trabajo es un compendio de artículos resultado de investigaciones, relacionados con la historia de la salud y la enfermedad en América Latina de Diego Armus (2002), Entre médicos y curanderos. Cultura, historia y enfermedad en América Latina. En la introducción el autor/compilador sugiere la reflexión histórica de la enfermedad en América Latina y propone preguntas de la relación entre salud y cultura. En cuanto a su compilación anota:

Muchos de estos estudios se proponen no solo como excursiones al interior de las medicinas folclóricas y las alternativas al saber diplomado y oficial, sino también como evidencias reveladoras de que la gente usa, combina o complementa incluso para objetivos que exceden los vinculados al cuidado y la asistencia- diferentes sistemas de atención de salud. (Armus, 2002, p.19)

En relación con el curanderismo, la compilación de Armus presenta dos textos sugerentes. El primero de Sowell (2002) "Andanzas de un curandero en Colombia: Miguel Perdomo Neira y "la lucha entre el buen sentido y la ignorancia ciega" relata las pericias que debe enfrentar un curandero -Perdomo- en 1872 frente a la naciente medicina diplomada en Colombia. La trifulca desatada en Santa Fe entre los defensores del curandero y los defensores del decano de la Facultad de Medicina de la Universidad Nacional, que alcanza a escalar el punto de la asonada al grito de "!Abajo los médicos, viva Perdomo!" y "!Abajo los perdomistas, mueran los fanáticos!” (Sowel, 2002, p. 73), es un antecedente de la manera como se va a trenzar en Colombia el debate entre lo que va a ser considerado científico y lo que forma parte de la superstición y la charlatanería.

En el segundo artículo, Palmer (2002) documenta la historia de Carlos Carballo Romero, espiritista y mago en Costa Rica en la segunda mitad de 1931 quien aprovechando sus dotes de espiritista se dedica a ejercer un tipo de medicina capaz de "curar enfermedades fuera del alcance de los tratamientos de la medicina oficial" (p. 261). Por este hecho fue acusado de practicar de manera ilegal la medicina y fue perseguido. Por encima de las acusaciones, "el profesor Carlos Carbell” como era conocido, tenía el prestigio que cualquier médico de medicina alternativa puede hoy tener.

El tercer escrito es de Silva Spitta (1993) quien realiza una lectura del diario "Naufragios" del conquistador Alvar Núñez Cabeza de Vaca, estableciendo la relación entre chamanismos y cristiandad. Importante destacar de allí la mención a algunas prácticas de curanderismo que aún perviven, pero igualmente importante la manera como Núñez Cabeza de Vaca reinterpreta estas prácticas con el cristianismo y cómo son reconocidas por los nativos americanos; algo que se mantiene actualmente en las prácticas terapéuticas de muchos curanderos a lo largo del país. Este es un trabajo documental y de análisis narrativo.

La importancia de estos trabajos radica en que históricamente analiza estas prácticas curativas en una perspectiva transcultural (Ceballos, 1995), de hibridación y mestizaje.

\section{La medicina tradicional como objeto de estudio de la antropología médica}

La exploración de la literatura existente sobre el tema encuentra que además de la antropología, la historia de las religiones y la historia cultural, la 
antropología médica (AM) al preguntarse por la relación salud/enfermedad/atención, explora esta tríada en su asociación con la cultura, lo cual la lleva a que sus investigaciones se entiendan con una diversidad de prácticas de curandería. A partir de las lecturas realizadas en el campo de la antropología médica (Fajreldin, 2006) o antropología de la medicina (Perdiguero y Comelles, 2000) es necesario considerar un análisis de la relación salud/ enfermedad/atención/cultura para: 1) revisar los trabajos e investigaciones que abordan las concepciones culturales de salud y enfermedad en diferentes culturas; 2) analizar cómo desde la AM se usa el concepto de cultura, y 3) registrar el uso que se hace de estas investigaciones en función de la formulación de políticas públicas en salud.

Tanto el artículo de Fajreldin -antropóloga social, chilena- como en el trabajo de investigación de los españoles Perdiguero y Comelles, que recoge una serie de ensayos resultado de investigaciones en el campo de la antropología de la medicina, enfocados a explorar el concepto de cultura y su relación con la salud y la enfermedad, coinciden en reconocer el carácter interdisciplinario y necesario de la $A M$, en tanto observan que los factores culturales han estado alejados y han sido desconocidos por la biomedicina. Este es un debate importante, ya que el reconocimiento del elemento cultural para la AM no quiere decir necesariamente que se validen los sistemas terapéuticos tradicionales como una opción para el tratamiento de la salud, la enfermedad y la atención; agregan que es justamente porque no hay investigaciones en este terreno que la gente opta por sistemas de atención médica distintas a la biomedicina. Para Perdiguero y Comelles (Ibíd. p. 34), dicho desconocimiento se traduce en "[...] una evidente y no desdeñable distancia cultural y actitudinal respecto a los modelos que, paso a paso, va proponiendo la biomedicina" (p. 34). Para Knipper (2006, p. 427), la categoría cultura en la AM más que respuesta debería ser pregunta y sugiere el término de medicina intercultural (Ibíd. p. 426) como el concepto que agrupa las prácticas y saberes médicos diferentes a la biomedicina. Este es uno de los debates teóricos que propone la AM para comprender la relación salud/enfermedad/atención.
Al respecto, un hallazgo importante en este estado del arte lo constituye la finalidad de las investigaciones en el campo de la AM: quién las promociona, desde dónde, para qué y qué relación tienen con el tema de medicinas tradicionales. Los países europeos, en particular España, han sido objeto de migraciones importantes de población de países de América Latina, África y Asia; poblaciones pobres que buscan mejores condiciones de vida o huyen de conflictos internos en sus países. Un problema a resolver está en el sistema de seguridad sanitaria que invierte recursos importantes, sin que sus resultados sean satisfactorios; algo que atribuyen a la ausencia del reconocimiento de factores culturales para la atención de la salud y la enfermedad. Con esta idea, se financiaron investigaciones (Fernández, 2006) en los diferentes países de donde provienen los inmigrantes. Estas investigaciones exploraron, entre varios aspectos, las concepciones de salud/enfermedad de comunidades indígenas en América Latina, la prestación de servicios sanitarios en países de árabes y las concepciones de salud intercultural en países del sur (Perdiguero y Comelles, 2000; Fernández, 2006). La intención fue incorporar este conjunto de prácticas, representaciones y sistemas simbólicos a la formación de su personal médico y al sistema de sanidad público, con el fin de optimizar recursos y lograr una mejor atención al paciente foráneo.

La investigación coordinada por Fernández (2006) Salud interculturalidad en América Latina. Antropología de la salud y crítica intercultural, financiada por varias instituciones académicas y organismos gubernamentales de España y publicada por Abya Yala (Ecuador) cuenta con 28 artículos resultado de investigaciones realizadas en terreno, con un enfoque interdisciplinario. Una ruta de exploración que abre la AM es la relación entre el funcionamiento de los sistemas sanitarios en países del sur y las concepciones culturales de salud. Sobre este tópico, el artículo ya citado de Knipper (2006) El reto de la 'medicina intercultural' y la historia de la 'medicina tradicional' indígena contemporánea problematiza la relación entre medicinas interculturales y servicios sanitarios, donde la pregunta por la cultura y las prácticas terapéuticas es fundamental al momento de orientar políticas públicas en sanidad. 


\section{El curanderismo como objeto de estudio cultural}

Las denominaciones de las prácticas curativas no facultativas o no diplomadas son conocidas también como curanderismo, medicina tradicional ${ }^{5}$, medicina popular o medicina casera. La antropóloga Virginia Gutiérrez de Pineda (1961) fue quien en Colombia adelantó uno de los primeros trabajos sobre curanderismo urbano y medicina popular. En su caracterización, equipara la medicina tradicional a la medicina facultativa al catalogarla como un sistema médico integrado a la cultura. De la medicina tradicional va a decir que tiene varias denominaciones: medicina preventiva que se fundamenta en principios mágicos; medicina folclórica, o etnomedicina, basada en sistemas tanto naturalísticos como personalísticos, curanderismo y medicina casera. Gutiérrez de Pineda (1961) caracteriza la práctica de la siguiente manera:

[...] la medicina tradicional, o como quiera llamársele, condensa el saber popular en relación con la salud, y se caracteriza porque: 1 . Constituye conocimientos y prácticas populares, integradas culturalmente; 2 . Se ajusta y funciona al ritmo del estudio tecnológico y científico de su entorno social; 3. Existe un trasfondo de creencia $\mathrm{y}$ fe individual y colectiva en ella, que fundamenta, estimula y dirige su acción. 4. Incorpora e innova con préstamos médicos foráneos, dentro de un complejo proceso aculturativo, que desciende de la avanzada médica -académica- y que paulatinamente es asimilado. 5. Se renueva con descubrimientos o hallazgos propios. 6. Da respuesta permanente a interrogantes de sus creyentes, $y$ eventual a extraños culturales, cuando se hallan recursos propios en emergencias de salud. 7 .

5 La Organización Mundial de la Salud (OMS) define la medicina tradicional (MT) como "la suma total de conocimientos, habilidades y prácticas basados en teorías, creencias y experiencias oriundos de las diferentes culturas, sean o no explicables, y usados en el mantenimiento de la salud, así como en la prevención, diagnosis o tratamiento de las enfermedades físicas o mentales" (consultado el 18 de febrero de 2014 en http://www.who.int/topics/traditional_medicine/es/). Los dos sistemas de MT más reconocidos en el mundo son la medicina china y la medicina ayurveda de la India. La definición de la OMS permite entonces incluir en esta clasificación los sistemas de salud indígena, afro y campesino.
Constituye un acto de comprobación a los postulados culturales, derivando un corpus médico integrado de pensamiento y acción, resultado interactuante del todo institucional. 8. Demuestra una cultura manifiesta en un ceremonial y prácticas, $y$ un contenido encubierto, de fe y creencia individual y de determinantes estructurales de la colectividad. (p. 27)

Un aporte importante de su trabajo lo constituye la caracterización mestiza que realiza de esta práctica.

Digamos inicialmente que nuestra medicina popular está conformada por una triple herencia de proporciones diferentes en su aporte. Mientras que parece que el legado de África es menor, España y América dieron un amplio contenido que, sin embargo, se vertió al patrón hispano. Así, sobrevive, en un amplio sincretismo, la cultura india con la peninsular, defendiendo la salud y curando sectores del pueblo colombiano. (Gutiérrez de Pineda, 1961, p. 7)

En este tema, un estudio relevante y que se ha convertido en clásico de la Antropología es "Colonialismo, chamanismo y el hombre salvaje: un estudio sobre el terror y la curación" del médico y antropólogo inglés Michel Taussig (2002) quien realiza una semblanza del chamanismo y de las prácticas del yagé en el sur del país. A partir de relatos que llegan a estar en la frontera del realismo mágico, el autor evidencia la manera como las prácticas de chamanismo indio se desplazan y se insertan en las zonas de colonización.

Trabajos posteriores sobre curanderismo en Colombia y la manera como estas prácticas se articulan y de alguna forma caracterizan y dinamizan la cultura popular urbana y rural lo realizan los profesores Carlos Pinzón y Rosa Suárez. En la primera investigación del profesor Pinzón (1988) Violencia y brujería en Bogotá, emprendida hacia 1976, se identifican redes de curanderos en Bogotá. Su investigación la adelanta en hospitales psiquiátricos de Bogotá donde determinan que la enfermedad mental de muchos de los pacientes es atribuida a causas de embrujamiento. Por esta vía dedican su trabajo a la localización de una red de curanderos y de usuarios 
de medicina tradicional (el autor no establece diferencias entre medicina tradicional y curanderismo y hace mayor énfasis en la subjetividad de los curanderos) en la ciudad, evidenciando tres aspectos que son centrales e importantes en la caracterización de los curanderos urbanos: la identificación de su procedencia de grupos indígenas de varias zonas del país (Putumayo, Caquetá, Amazonas) asentados en la ciudad a partir de procesos de migración de sus regiones por distintas razones, su capacidad de adaptación de su práctica curativa al medio urbano y su facilidad para difundir sus conocimientos entre pobladores urbanos, que se va a traducir en la proliferación de curanderos urbanos caracterizados por el mestizaje de su práctica. La segunda investigación Las mujeres lechuza (Pinzón y Suárez, 1992) es resultado del proyecto de investigación "Salud y medicina tradicional en Colombia” auspiciado por el Instituto Colombiano de Antropología. Allí, se exponen los resultados de la indagación en torno al mito de las brujas en el municipio de Sora (Boyacá). En líneas generales el libro articula problemas relacionados con la construcción de nociones de salud-enfermedad (mental) en situaciones de conflicto entre lo científico y lo popular, el desplazamiento de prácticas de curanderismo del campo a la ciudad, la presencia de elementos indígenas en las prácticas de brujería y curanderismo en una zona rural de Boyacá y el cuerpo como objeto de colonización y de conflicto.

Un trabajo con reflexiones similares y de aparición por el mismo tiempo, es el de los profesores Urrea (1989) y Jara (1990) quienes caracterizan la presencia urbana de curanderos en las ciudades del suroccidente del país (Cali, Popayán, Buenaventura, Pasto) a partir de la descripción de "una modalidad de prácticas de curación popular de tradición indígena con capacidad de inserción en los espacios urbanos, configurado a partir de 'otras culturas' una imagen de antimodernidad en el campo de la salud" (p. 126). Un aspecto a destacar de esta investigación tiene que ver con la preocupación que manifiestan los autores en el sentido de que a pesar de los avances de la medicina facultativa y sus técnicas, esta no ha podido contrarrestar la presencia del curanderismo indígena. Tanto el trabajo de la profesora Gutiérrez, de los profesores Pinzón, Suárez y Urrea y del antro- pólogo Taussig pueden ser considerados fundantes en términos de la identificación de la práctica del curanderismo en Colombia, en la perspectiva de su hibridación con los saberes indígenas.

El análisis híbrido del curanderismo aparece igualmente en trabajos sobre curanderos en el Perú. Al respecto, Tomoeda (1992, p. 183) afirma: "Estudiar el curanderismo cuzqueño es abrir la puerta de un proceso que muestra las muchas caras del mestizaje moderno". Este artículo describe la hibridación en relación no solo con el contacto entre culturas hispanas y regionales (la Costa Norte, Bolivia) si no con la medicina moderna y con el dogma católico dominante, y presenta al curandero cuzqueño como un "personaje vital para la comprensión de la sociedad peruana" (p. 183). En esta misma dirección, trabajos acerca de curanderismo en España (Martínez, 1996) si bien no reconocen su carácter híbrido sí su diversidad de orígenes. $\mathrm{Al}$ respecto el autor señala que "La medicina popular o rural nace de la diversidad de orígenes cuyo inicio evidentemente fueron las tradiciones mágicas y las artes de hechicería". (p. 165)

De igual manera, estos artículos apuntan a identificar algunas características que van a ser recurrentes en otros trabajos sobre el curanderismo: la relación entre magia, religión y medicina, como parte de los elementos que forman parte de la técnica curativa de los curanderos. En esta relación tríadica está la explicación de su poder curativo. El primer elemento, la magia, constituye un sistema de prácticas de las cuales hace parte la "hechicería, la brujería, el chamanismo, la yerbatería, el curanderismo y la adivinaciones" (Ceballos, 2002, p. 101). Su eficacia simbólica radica tanto en la posibilidad de producir el bien como la de causar daño:

Cuando los curanderos hablan del daño lo hacen en relación a su capacidad para recocerlo y subsanarlo. Ninguno asevera utilizar sus conocimientos para causarlo; por el contrario, juzgan negativamente a quienes lo hacen. (Oliszewski, 2012, p.170)

Ina Rösing (2008) por su parte, adelanta un trabajo etnográfico sobre el curanderismo kallawalla 
en Bolivia, un buen ejemplo de una modalidad de curación ritual donde la magia en los rituales nocturnos de curación de esta comunidad cumple un papel preponderante. La autora denomina a estos elementos formas curativas rituales y simbólicas (2008, p. 46).

En cuanto a lo religioso, en el artículo ya citado de Tomoeda (1992, p. 189) afirma acerca del curanderismo cuzqueño:

[...] el curanderismo no plantea una fe distinta a la cristiana, más aun los "naturistas" se confiesan profundamente devotos. Pero establecen claras diferencias entre el accionar de ellos y los apus y el de los sacerdotes y el panteón católico. Cuando se pide un milagro a la iglesia oficial, se espera solucionar un problema, y esto puede o no suceder así, lo que no se espera es comprender la mecánica de lo sucedido. El paciente o demandante recuperará su cónyuge o sanará de la enfermedad, pero no tendrá mayores explicaciones que su propia fe en determinado santo o virgen. Lo que el curandero le ofrece, es un sistema lógico de interpretación del universo que lo rodea, en el que sus males solo son una parte que puede ser solucionada.

La religiosidad cumple igualmente una función de validación social y cultural para el curandero que encuentra en ella la explicación de sus virtudes terapéuticas. Su poder proviene de dios y es en virtud de sus creencias religiosas que obra la curación. Esto necesariamente implica una relación de acuerdo con aquellos que emplean sus servicios, llegando en ocasiones a constituir comunidades de carácter confesional donde no solo se profesa la fe por convicción, sino que se acompaña de la celebración de rituales de curación cargados de imágenes religiosas que operan como benefactores, ayudantes e intermediarios para lograr el éxito en la curación. Si el enfermo logra sanarse no será por otra razón distinta a la intermediación del curandero con dios.

El elemento médico -es decir, con los procedimientos de diagnóstico, formulación de medicamentos, realización de intervenciones quirúrgicas y seguimiento a tratamientos de ciertas enfermedades- no es tratado de manera amplía en los textos compilados. Esto al menos en lo que corresponde a la literatura (excepto el trabajo de Oliszewski, 2012) ubicada y que está referenciada a la producción de los años 60 a 90. Muy seguramente el auge de las medicinas verdes entre las que se cuentan las medicinas tradicionales y populares, hará proliferar el interés por parte de la medicina diplomada de algunas técnicas terapéuticas tradicionales y uso de algunas plantas medicinales, lo que desembocará en la producción de nuevos artículos académicos.

Otras perspectivas de análisis las aporta la $\mathrm{AM}^{6}$ que sitúa las prácticas de curanderismo como formas diferenciadas culturalmente de atención a la salud y la enfermedad e introduce el debate de la salud pública. En este sentido, la AM considera como un valor importante en los sistemas médicos tradicionales la integralidad de sus concepciones sobre la enfermedad y la salud. Gurung (citado por Porras y Álvarez, 2013) afirma: "En muchas sociedades existen abordajes integrales que toman en cuenta varias dimensiones personales en lugar de enfocarse solamente en la presencia o ausencia de enfermedades físicas para determinar la salud", crítica dirigida al modelo biomédico hegemónico imperante en cuanto se refiere a atención y cuidado de la salud y la enfermedad, al menos en Occidente.

Es importante señalar que la literatura consultada muestra una preocupación de autores como Menéndez (1994) por definir términos como medicina tradicional, curanderismo y curandero (Gómez, 1996) buscando establecer los límites de su acción terapéutica dentro de una práctica curativa no facultativa pero de reconocimiento social y con efectos sobre las prácticas culturales para la atención de la enfermedad y la salud. Menéndez (1994), en la definición de medicina tradicional, advierte acerca de "una serie de constantes y tendencias que dificultan la interpretación de lo que constituye dicha medicina" (p. 74), las cuales serían: la referida a grupos que a priori son definidos como tradicionales (grupos étnicos amerindios, el campesinado indí-

6 Uno de los trabajos pioneros de la antropología médica (AM) en México es el de Aguirre (1994). Igualmente importante en la perspectiva relacional, la obra extensa de Eduardo Menéndez. 
gena, el criollo o el mestizo); la que opone medicina tradicional a medicina científica y la que piensa la MT como no modificable, poco modificable o no modificable en lo sustantivo (pp. 74-75). En relación con este debate, el autor hace una propuesta analítica interesante que permite explorar la MT en una dinámica relacional y contextual que evita el trabajo de definir un campo como el curanderismo, sin caer en alguna de las advertencias que hace el autor en relación con la definición de MT. Frente a esto dice:

Es en el "sistema" funcionando que veremos operar procesos de síntesis, de yuxtaposición o de exclusión de prácticas y representaciones procedentes de diferentes saberes, pero que, en los conjuntos sociales, se organizan de una determinada manera. Es en la descripción y análisis de estos procesos relacionales que observaremos el lugar que ocupa lo "tradicional" o lo "científico", pero lo haremos en términos del sistema de prácticas y representaciones que está teniendo lugar en la realidad de un enfermo atendido en el hogar o por una hierbera, o por un médico alópata, o por un espiritualista, o como puede ocurrir por todos ellos en forma sucesiva. (Menéndez, 1994, p. 75).

Este planteamiento permite establecer al menos dos maneras de analizar la práctica del curanderismo. Una relacional donde se analizan sistemas de prácticas vinculadas con comunidades específicas y otra por identificar y describir prácticas de curanderos in situ más desde la perspectiva del curandero sujeto. Esta última perspectiva obedece, en algunos casos, a una posición política que se pregunta por el lugar de lo étnico en la construcción de identidades nacionales y la importancia de saberes locales frente a saberes globales hegemónicos. Una particularidad entre la literatura elaborada desde investigaciones en Suramérica y Centroamérica, principalmente y la producida en España es que las definiciones y elaboraciones sobre MT y en general de sistemas de medicina popular por los primeros, es que llevan implícito un debate sobre la geolocalización del conocimiento y de los saberes, haciendo alusiones permanentes a una perspectiva que cuestiona la colonialidad del saber (Lander, 2000). Para el caso de la producción española (al menos la revisada hasta los años 1990) habría que decir que su preocupación está más centrada en la descripción de estas prácticas como parte de la cultura ibérica y en alguna medida un debate con la medicina diplomada. Esta perspectiva, sin embargo, se ha transformado por los procesos migratorios de África y América hacia España que, como ya se señaló, al menos hasta antes de la crisis económica española, habían generado una pregunta por la pertinencia del tema cultural como un factor para el diseño de políticas públicas en salud.

Investigaciones más recientes abordan nuevos problemas que plantea un curanderismo que se hace más global, diversificado y transcultural y que tiene incidencia sobre la producción de nuevas subjetividades y prácticas colectivas. Dentro de estos trabajos está la tesis de maestría en Antropología de la Universidad Nacional de Colombia de Leonardo Benavides (2012), Curanderismo en Bogotá: entre la 'razón' y la 'sinrazón', investigación que analiza las "concepciones y prácticas empleadas por un curandero en la ciudad de Bogotá"; el artículo de Losonczy y Mesturini (2010) "La selva viajera. Rutas del chamanismo ayahuasquero entre Europa y América", quienes analizan la itinerancia multidireccional ( $\mathrm{p}$. 166) y de movilidad de chamanes proveedores de ayahuasca a Europa; dos trabajos de Alhena Caicedo: el artículo "Neochamanismos y modernidad. Lecturas sobre la emancipación" (2007), y su tesis en antropología social La alteridad radical que cura. Los nuevos lugares del chamanismo en Colombia (2013), en la que analiza las nuevas formas de chamanismo en Colombia; la tesis doctoral de Nadège Mazars (2012), Les ruses de la pratique subalterne: La santé gérée par les autochtones en Colombie, un multiculturalisme de domination et/ou d'autonomie?, quien analiza problemas de institucionalización de medicinas tradicionales en tres comunidades indígenas en Colombia y su relación con la creación de EPS indígenas.

Varios artículos, en particular los escritos desde los años 1970 hasta la década de 1990, coinciden en situar el curanderismo como una opción popular, 
limitada a resolver asuntos de mala suerte o de mal de amores; definidas como enfermedades culturales (Peretti, 2010; Guzmán, 1993; Oliszewski, 2012)7. En relación con las enfermedades culturales, la compilación ya citada de Fernández (2006) presenta al menos tres artículos que sirven de ejemplo para realizar un acercamiento al concepto de enfermedad cultural: El samay, el susto y el concepto de persona en Ayacucho, Perú de Isabel Neila Boyer (2006); ¿Fármacos contra el susto? Paradojas y posiciones enfrentadas en la concepción de la enfermedad en el altiplano boliviano de Francisco Gil (2006); y Curación de una enfermedad espiritual desde una perspectiva aymara de Raquel Nava (2006).

En relación con problemáticas actuales de las cuales se vienen ocupando las Ciencias Sociales, como el género, la etnia y la clase, no se evidencia una producción amplía al menos en los temas de género y clase. En este punto las investigaciones localizadas son: "Mujeres, cosmovisión y medicina: las curanderas mexicanas" (Marcos, 1989) y "Medicina tradicional de la mujer inga" (GiraldoTafur, 2000).

Por último, es importante mencionar al menos dos trabajos cuya fuente teórica no es la antropología sino la etnografía del habla y la semiótica. El primero es resultado de una tesis de la maestría en Lingüística de la Universidad Nacional de Colombia, titulado "Rezar, soplar, cantar: etnografía de una lengua ritual" (Garzón, 2004), el cual, mediante un análisis desde la etnografía del habla, elabora un estudio de un ritual de curandería donde se emplea el yagé. Este trabajo puede ser leído como un protocolo de iniciación en curanderismo. El segundo, "Curanderismo y magia. Un análisis semiótico del proceso de sanación" (García y Rangel, 2010) argumenta que la curación como proceso psicológico responde al discurso y al acercamiento del curandero hacia el paciente. Estos trabajos aportan otras posibilidades de análisis del fenómeno.

7 Para comunidades indígenas en Amazonas, el chisme es considerado una enfermedad que viene asociada al cambio de época en el calendario ecológico tradicional. Esta corresponde con el tiempo de la chicharra (Quesada gigas).

\section{Conclusiones}

El estado del arte descrito permite identificar las medicinas tradicionales y populares como un tema de tratamiento interdisciplinar, relacionado con prácticas mágicas como el chamanismo, la yerbatería y el curanderismo. La amplia producción de artículos que describen y caracterizan algunas prácticas de chamanismo y curanderismo en Centroamérica, Suramérica y España muestran su diversidad, su capacidad de permanencia, de sincretismo y mestizaje. Al respecto, los estudios recopilados y analizados en este artículo problematizan las nociones correspondientes a lo hibrido y lo mestizo, en una perspectiva transcultural (Ortiz, 1999) al mostrar cómo las prácticas de medicina tradicional y popular no solo apropian y amalgaman saberes y técnicas curativas diversas, sino que también pueden perder elementos de la tradición que las originó, provocando así una transformación en sus epistemes, con incidencia en el tiempo en las prácticas colectivas de sus allegados.

La literatura rastreada prioriza el análisis por las figuras del chamán y el curandero (esto al menos en los artículos y trabajos hasta los años 1990) y deja al margen a sus usuarios o pacientes; quienes no gozan del mismo prestigio cultural que los primeros. Al respecto, algunos artículos solo toman apartes de entrevistas de pacientes con el fin de ratificar la eficacia del curandero. En este punto no se visualizan estudios que analicen al paciente, a quien asiste en busca de sus servicios y la manera como incorpora en su cotidianidad estos saberes para el cuidado de su salud y la atención de la enfermedad, si los incorpora, los recrea o si el curandero funge como sacerdote que le permite mantener un estado de creencias.

Además de mostrar la vigencia del tema, el estado del arte evidencia la necesidad de ahondar -al menos en Colombia- en las relaciones entre sistemas terapéuticos tradicionales, cultura y salubridad, con miras a la formulación de políticas públicas que permitan no solo el reconocimiento de estos saberes, sino también su regulación y apoyo estatal. 


\section{Referencias bibliográficas}

Aguirre, G. (1994). Programas de salud en la situación intercultural. México: Fondo de Cultura Económica.

Amselle J.L. (2008). Retour sur "l'invention de la tradition". L'Homme, 1-2 (185-186), 187-194.

Armus, D. (2002). Entre médicos y curanderos. Cultura, historia y enfermedad en la América Latina moderna. Buenos Aires: Editorial Norma.

Benavides, L. (2012). Curanderismo en Bogotá: entre la "razón" y la "sinrazón". Tesis de maestría. Bogotá: Universidad Nacional de Colombia.

Bidou, P. (Julio, 1988). Sintaxis y eficacia del discurso chamanico (Amazonía colombiana). En: simposio del $45^{\circ}$ Congreso Internacional de Americanistas, 35-48. Simposio llevado a cabo en Bogotá. Quito, Abya Yala.

Boyer, I.N. (2006). El samay, el susto y el concepto de persona en Ayacucho, Perú. En: G. Fernández (ed.). Salud e interculturalidad en América Latina. Antropología de la salud y crítica intercultural, 187-215. Quito: Ediciones Abya Yala.

Caicedo, A. (2007). Neochamanismos y modernidad. Lecturas sobre la emancipación. Revista Nómadas, 26, 114-127.

Caicedo, A. (2013). La alteridad radical que cura. Los nuevos lugares del chamanismo en Colombia. Tesis de doctorado. París: École des Hautes Études en Sciences Sociales.

Cayón, L. (2002). En las aguas de yurupari: cosmología y chamanismo Makuna. Bogotá: Ediciones Uniandes.

Ceballos, L. (1995). Hechicería, brujería e inquisición en el Nuevo Reino de Granada. Un duelo de imaginarios. Medellín: Editorial Universidad Nacional de Colombia.

Ceballos, L. (2002). Sociedad y prácticas mágicas en el Nuevo Reino de Granada. Bogotá: Ministerio de Cultura.

Chamueil, J. (1998). Ver, saber, poder: el chamanismo de los yagua de la Amazonia peruana. Perú: Centro Amazónico de Antropología y aplicación Práctica (CAAAP), Instituto Francés de Estudios Andinos (IFEA), Centro Argentino de Etnología Américana (CAEA-CONICET).

Echeverry, J. (comp.). (1993). Tabaco frío, coca dulce. Bogotá: Colcultura.

Eliade, M. (1994). El chamanismo y las técnicas arcaicas del éxtasis. México: Fondo de Cultura Económica.
Evans-Pritcher, E.E. (1976). Brujería, magia y oráculos entre los azande. Barcelona: Anagrama.

Fajreldin, V. (abril-junio de 2006). Antropología médica para una epidemiología con enfoque sociocultural. Elementos para la interdisciplina. Ciencia y trabajo 8(20), 95-102. Recuperado de: http://es.scribd.com/ doc/36191375/Antropologia-medica

Fernández, G. (ed.). (2006). Salud e interculturalidad en América Latina. Antropología de la salud y crítica intercultural. Quito: Ediciones Abya Yala.

García, R. y Rangel, E. (2010). Curanderismo y magia. Un análisis semiótico del proceso de sanación. Revista CULCyT 7(38/39), 5-15.

Garzón, O. (2004). Rezar, soplar, cantar. Etnografía de una lengua ritual. Quito: Ediciones Abya Yala.

Gil, F. (2006). ¿Fármacos contra el susto? Paradojas y posiciones enfrentadas en la concepción de la enfermedad en el altiplano boliviano. En: G. Fernández (ed.). Salud e interculturalidad en América Latina. Antropología de la salud y crítica intercultural, 217-227. Quito: Ediciones Abya Yala.

Giraldo-Tafur, C. (2000). Medicina tradicional de la mujer inga. Revista Academia Colombiana de Ciencias 24(90) 5-23.

Gómez, P. (1996). Teorías étnicas y etnológicas sobre la terapéutica popular. En: A. González y B., Rodríguez. Creer, curar: la medicina popular. (pp. 1-26). Granada. Recuperado de: http://pedrogomez.antropo.es/ capitulos/1996-Teorias-etnicas-y-etnologicas-sobrela-terapeutica-popular.pdf

Gutiérrez de Pineda, V. (1961). La medicina popular en Colombia. Razones de su arraigo. Bogotá: Universidad Nacional de Colombia.

Guzmán, M. (1993). Salud-enfermedad y las enfermedades tradicionales en Pustunich, Yucatán En: Perspectivas antropológicas en el mundo maya. Recuperado de: http://dialnet.unirioja.es/servlet/ articulo? codigo $=2776160$

Jara, M. (1990). Dinámica etnohistórica sociodemográfica y presencia contemporánea del curanderismo ingano-kamsá en las ciudades colombianas. Boletín socioeconómico, (20) 123-156.

Knipper, M. (2006). El reto de la "medicina intercultural" y la historia de la "medicina tradicional" indígena contemporánea. En: G. Fernández (ed.). Salud e interculturalidad en América Latina. Antropología de la salud y crítica intercultural, 413-432. Quito: Ediciones Abya Yala. 
Lander, E. (ed.). (2000). La colonialidad del saber: eurocentrismo y ciencias sociales. Perspectivas latinoamericanas. Buenos Aires: Clacso.

Losonczy, A. y Mesturini, S. (2010). La selva viajera. Rutas del chamanismo ayahuasquero entre Europa y América. Religião e Sociedade, Rio de Janeiro 30(2), 164-183.

MacClancy, J. (2002). Exotic No More. Anthropology on the Front Lines. Chicago y Londres: The University of Chicago Press.

Marcos, S. (1989). Mujeres, cosmovisión y medicina: las curanderas mexicanas. En: B. García; O. de Oliveira; G. Roel y E. Tuñon. Trabajo, poder y sexualidad. México: El Colegio de México, 359-382. Recuperado de: https://sylviamarcos.files.wordpress. com/2009/04/las-curanderas-mexicanas.pdf

Martín-Barbero, J. y Ochoa, A. (2005). Políticas de la multiculturalidad y desubicaciones de lo popular. En: D. Mato. Cultura, política y sociedad Perspectivas latinoamericanas, 181-197. Buenos Aires: Consejo Latinoamericano de Ciencias Sociales (Clacso).

Martínez, S. (1996). Superstición y medicina popular. Revista de Estudios Yeclanos, 7, 165-172.

Mazars, N. (2012). Les ruses de la pratique subalterne: la santé gérée par les autochotones en Colombie, un multiculturalisme de domination et/ou d'autonomie? Tesis de doctorado. Université Sorbonne Nouvelle - París III. Institut des Hautes Études de l'Amérique Latine.

Menéndez, E. (1994). La enfermedad y la curación. ¿Qué es la medicina tradicional? Alteridades 4(7), 71-83. Recuperado de: http://biblioteca.ues.edu.sv/revistas/10800276-8.pdf

Nava, R. (2006). Curación de una enfermedad espiritual desde una perspectiva aymara. En: G. Fernández. Salud e interculturalidad en América Latina. Antropología de la salud y crítica intercultural, 245-256. Quito: Ediciones Abya Yala.

Oliszewski, D. (2010). La figura de dios como estrategia legitimadora de las prácticas terapéuticas de los curanderos. Eä, Buenos Aires 2(2), 1-20. Recuperado de: http://www.ea-journal.com

Oliszewski, D. (2012). Según la curandera era un mal que nos habían hecho. Estigma, poder y subalternidad: la noción de daño dentro del curanderismo. Revista Sociológica de Pensamiento Crítico 6(2), 165-174.

Organización Mundial de la Salud (OMS). ¿Qué es la medicina tradicional? Recuperado de: http://www. who.int/topics/traditional_medicine/es/
Ortiz, F. (1999). Contrapunteo cubano del tabaco y el azúcar (Advertencia de sus contrastes agrarios, económicos, históricos y sociales, su etnografía y su transculturación). Barcelon: Edito Cuba España.

Palmer, S. (2002). La voluntad radiante del profesor Carbell: medicina popular y populismo médico en Costa Rica en el decenio de 1930. En: D. Armus (comp.) Entre médicos y curanderos. Cultura, historia y enfermedad en la América Latina moderna, 261-292. Buenos Aires: Editorial Norma.

Perdiguero, E. y Comelles, J. (comp.) (2000). Medicina y cultura. Estudios entre la antropología y la medicina. Barcelona: Edicion Bella Terra.

Peretti, L. (2010). Las “enfermedades culturales", la etnospsiquiatría y los terapeutas tradicionales de Guatemala. Revista Scripta Ethnologica, 32, 17-28. Recuperado de: http://www.redalyc.org/ pdf/148/14815618002.pdf

Perrin, M. (Julio, 1985). Formas de comunicación chamanica. El ejemplo guajiro (Venezuela y Colombia). En: simposio del $45^{\circ}$ Congreso Internacional de Americanistas, 61-79. Simposio llevado a cabo en Bogotá. Quito, Abya Yala.

Pinzón, C.E. (1988). Violencia y brujería en Bogotá. Boletín cultural y bibliográfico 16(25). Recuperado de: http://publicaciones.banrepcultural.org/index.php/ boletin_cultural/article/view/2792/2872

Pinzón, C.E. y Suárez, R. (1992). Las mujeres lechuza. Historia, cuerpo y brujería en Boyacá. Bogotá: CEREC, ICAN.

Porras, A y Álvarez, A. (2013). La medicina tradicional como un modelo de atención integral en salud. Revista de la Universidad del Valle de Guatemala, 25, 58-60.

Reichel-Dolmatof, G. (1978). El chamán y el jaguar. Bogotá: Siglo XXI Editores.

Reichel-Dolmatof, G. (1997). Chamanes de la selva pluvial. Ensayos sobre los indios tucano del noroeste amazónico-Gaia. Londres: Green Books.

Rösing, I. (2008). Defensa y perdición: la curación negra. Rituales nocturnos de curación en los Andes bolivianos. Madrid: Iberoamericana Vervuert.

Sowell, D. (2002). Andanzas de un curandero en Colombia: Miguel Perdomo Neira y la lucha entre el buen sentido y la ignorancia ciega. En: D. Armus (comp.) Entre médicos y curanderos. Cultura, historia y enfermedad en la América Latina moderna, 71-103. Buenos Aires: Editorial Norma. 
Universidad Pedagógica Nacional

Facultad de Humanidades

Spitta, S. (1993). Chamanismo y cristiandad: una lectura de la lógica intercultural de los "Naufragios" de Cabeza de Vaca. Revista de Crítica Literaria Latinoamericana 38(19), 317-330. Recuperado de: http:// www.jstor.org/stable/4530696

Strauss, C. (1995). Antropología estructural. México: Siglo XXI Editores.

Taussig, M. (2002). Chamanismo, colonialismo y el hombre salvaje: un estudio sobre el terror y la curación. Bogotá: Editorial Norma.

Tomoeda, H. (1992). Curanderos urbanos: salud y ritual en el Cuzco contemporáneo. Recuperado de: http:// ir.minpaku.ac.jp/dspace/bitstream/10502/672/1/ SES33_009.pdf.

Urrea, F. (1989). Curanderismo indígena y antimodernidad en los espacios urbanos del suroccidente colombiano. Boletín socioeconómico, 19. 